\title{
Influence of Organotin on Thyroid Morphophysiological Status
}

\author{
Paula Rodrigues-Pereira ${ }^{1,2}$, Celia Palmero ${ }^{3}$, Rômulo Medina de Mattos ${ }^{3}$, Diorney Luiz Souza Gran \\ da Silva ${ }^{4}$, Ana Paula Santos-Silva ${ }^{1,2}$, Jones Bernardes Graceli ${ }^{5}$, Paula Soares ${ }^{6}$, Luiz Eurico Nasciutti ${ }^{3}$, \\ Denise Pires de Carvalho ${ }^{2,4}$, Andrea Claudia Freitas Ferreira ${ }^{2,7}$, Leandro Miranda- Alves ${ }^{1,2 *}$
}

\author{
${ }^{1}$ Research Group of Experimental Endocrinology-GPEEx, Institute of Biomedical Sciences, Federal University of Rio de Janeiro, Brazil \\ ${ }^{2}$ Postgraduation Program in Endocrinology, Faculty of Medicine, Federal University of Rio de Janeiro, Brazil \\ ${ }^{3}$ Cell Interactions Laboratory, Institute of Biomedical Sciences, Federal University of Rio de Janeiro, Brazil \\ ${ }^{4}$ Institute of Biophysics Carlos Chagas Filho, Federal University of Rio de Janeiro, Brazil \\ ${ }^{5}$ Department of Morphology, Federal University of Espirito Santo, Brazil \\ ${ }^{6}$ Cancer Biology Group, Institute of Molecular Pathology and Immunology of the University of Porto, Porto, Portugal \\ ${ }^{7}$ Institute of Biophysics Carlos Chagas Filho / Campus Xerem, NUMPEX, Federal University of Rio de Janeiro, Brazil
}

*Corresponding author: Prof Dr Leandro Miranda-Alves, Universidade Federal do Rio de Janeiro, Centro de Ciências da Saúde, Institute de Ciências Biomédicas, Grupo de Pesquisa em Endocirnologia Experimental -GPEEx, Av. Carlos Chagas Filho, 373, Bloco G- Sala G1- 060 - Ilha do Fundão, 21941 -912; Rio de Janeiro, RJ, Brazil, E-mail: alvesmpi@hotmail.com/lmiranda@ufrj.br

\begin{abstract}
Tributyltin is an environmental contaminant found in antifouling paints, widely used in ships and other vessels. TBT causes endocrine-disrupting effects in mammals, due to its possible transfer through marine food chains, and the consequent consumption of contaminated seafood. Thus, we aimed to evaluate whether the treatment with TBT could induce histophysiological changes in the thyroid gland. TBT promoted disorganization of parenchyma, fibrosis and vascular congestion in the gland. Moreover, morphometric analysis showed statistically significant changes in the follicle of rats treated with TBT, with increased colloid and epithelial area, besides increased epithelial/colloid area relation, but no statistical differences were found in epithelial height. Nevertheless, collagen deposition was seen in the thyroids of treated groups. In thyroid physiological status, we did not observe intergroup significant changes in plasma levels of total $T_{3}$ and $T_{4}$ after treatment, even though we have found a time-dependent increase of $\mathrm{T}_{4}$ levels in TBT-treated groups. We also detected an increased $\mathrm{H} 2 \mathrm{O} 2$ production in the thyroid of TBT-treated group, besides increased dual oxidase protein levels, the main enzyme involved in hydrogen peroxide production. Since $\mathrm{H} 2 \mathrm{O} 2$ is a reactive oxygen species, TBT could induce oxidative stress, what could be involved in the morphophysiological changes observed in the gland. These data provided the evidence that exposure to TBT induces morphophysiological changes in the thyroid gland, and may therefore correspond to a potential risk factor for thyroid disorders.
\end{abstract}

Keywords: Tributyltin chloride; Thyroid; Histophysiology; Thyroperoxidase; Dual oxidases; $\mathrm{H} 2 \mathrm{O} 2$ generation

\section{Introduction}

Tributyltin (TBT) is a chemical substance classified as organotin (OT). OT compounds represent a class of organometallic compounds containing at least one $\mathrm{C}$-Sn bond per molecule, predominantly formed from tetravalent $\operatorname{tin}^{[1]}$. In the early 70 's, the first report about the harmful effects of TBT on organisms came to light, thus rendering TBT a classification as pollutant/toxic substance ${ }^{[2]}$. However, due to the low cost, TBT has been widely used as addictive in antifouling paints. Despite the organotin efficiency, it has been considered the most toxic chemical to sensi-
Received Date: June 18, 2015

Accepted Date: July 13, 2015

Published Date: July 17, 2015

Citation: Rodrigues-Pereira, et al. Influence of Organotin on Thyroid Morphophysiological Status. (2015) J Environ Health Sci 1(3): 1-7.

\section{DOI: $10.15436 / 2378-6841.15 .018$}

tive organisms deliberately introduced into marine ecosystems, and the consumption of contaminated marine species leads to human dietary exposure to this compound $^{[3-6]}$. Therefore, because of the extreme toxicity of TBT at the different trophic levels and experimental models, it is considered an ecotoxicological product. The first adopted regulation on the use of TBT as a biocide in antifouling paints appeared in 1982, and was introduced by the French Ministry of the Environment to reduce the use of $\mathrm{TBT}^{[7]}$. However, this regulation was not widespread, due to the economic importance of these industrial paints used in worldwide shipping ${ }^{[3,8,9]}$. Environment contamination with organotin has been biomonitored by determining the imposex syndrome rate. Imposex is characterized by the appearance of a penis and/or vas deferens in female gastropods, and remains seen in Brazilian gastropod

Copy rights: (C2015 Rodrigues-Pereira et al. This is an Open access article distributed under the terms of Creative Commons Attribution 4.0 International License. 
populations, as in other countries, even after the TBT ban ${ }^{[9]}$. Populations of these species were analyzed in the coast of Rio de Janeiro (Brazil) between 2007 and 2008, and the developmental defects associated with the syndrome were identified. Comparing their recent work with previous, Toste et al. (2013), have noticed that imposex was reduced in most part of the Guanabara Bay, Rio de Janeiro, Brazil; however, aphallic imposex development showed a marked increase.

A review of the literature indicates that TBT exposure can produce endocrine disruptive effects. It was reported that TBT can alter the sex ratio in favor of males in the zebrafish and Paralichthys olivaceus; besides promoting inhibition of thyroid function and testicular development in the fish species Sebastiscus marmoratus ${ }^{[10]}$. Adeeko et al ${ }^{[11]}$ (2003) investigated the effects of tributyltin exposure on the pregnancy outcome in Sprague-Dawley rats. In this study, one of the results found was that the serum levels of thyroxine $\left(\mathrm{T}_{4}\right)$ and 3,5,3'-triiodothyronine $\left(\mathrm{T}_{3}\right)$ were significantly reduced in dams exposed to 10 and $20 \mathrm{mg} / \mathrm{kg}$ body weight tributyltin throughout gestation. In dams treated with TBT during gestational days 8-19, serum thyroxine concentrations, but not triiodothyronine, were significantly decreased at both doses ( 2.5 and $10 \mathrm{mg} / \mathrm{kg}$ body weight) of exposure. Since thyroid hormones play an important role during development, these data raised the question about the contribution of maternal thyroid disruption mediating the developmental toxicity of organotins. Similarly, male pups from mothers treated with $2.5 \mathrm{mg} / \mathrm{kg} /$ day TBT from day 8 of gestation until weaning showed reduced serum thyroxine levels, thus indicating that the thyroid gland is a target for TBT toxicity ${ }^{[12]}$.

Recently, it was observed that in Xenopus laevis exposed to TBT for a period of 19 days at the concentrations of $12.5-200 \mathrm{ng} / \mathrm{L}$, there was a decrease in the number of thyroid follicles, associated to thyroid follicle hyperplasia ${ }^{[13]}$. These data demonstrate that the thyroid is a very sensitive target of TBT exposure. Thus, the reduction of thyroid hormones could produce deleterious on different functions attributed to thyroid hormones on target-organs. Recently, Sharan et $\mathrm{al}^{[14]}$ demonstrated that chronic exposure to low doses of TBT promotes suppression of TR transcription by disrupting the physiological concentrations of $\mathrm{T}_{3} / \mathrm{T}_{4}$.

Therefore, if we consider the importance of OT as environmental endocrine disruptor in different animal models, it is of fundamental importance to elucidate the effects of TBT effects on thyroid gland of mammals, which currently are poorly understood. This gland is the first endocrine gland to emerge during the development, and produces hormones $\left(\mathrm{T}_{3}\right.$ and $\left.\mathrm{T}_{4}\right)$ that have important role on growth, development, metabolism and thermoregulation. Thus, in the present work, we aimed to evaluate the effects of short term exposure to TBT on thyroid morphology and physiological status in male Wistar rats treated with different concentrations of TBT.

\section{Materials and Methods}

\section{Animals and Treatment}

In the present study, we used adult male Wistar rats weighing 230-250 g, eight weeks old, exposed to TBT over a 15 day period. All animals were kept under controlled conditions of light/dark (12/12 hours) and temperature $\left(37^{\circ} \mathrm{C}\right)$ and had access to pelleted commercial chow and water ad libitum. The Institu- tional Committee for Use of Animals in Research approved the study (Code: DAHEICB082), and the procedures were in compliance with the International Guiding Principles for Biomedical Research Involving Animals of the Council for International Organizations of Medical Sciences (Geneva, Switzerland), and the guiding principles for care and use of animals from the American Veterinary Medical Association. TBT chloride was purchased from Sigma-Aldrich S.A. (San Diego, USA) and the purity of the substance is $96 \%$. Animals $(n=5 /$ experimental group, three independent experiments) were randomly assigned to three groups, one of which served as a control group (treated only with the vehicle $-0.4 \%$ ethanol), while the other two groups were treated with two different doses of TBT. The male Wistar rats were treated orally with $500 \mathrm{ng} \mathrm{TBT} / \mathrm{kg}$ (body weight)/day or $1000 \mathrm{ng}$ TBT $/ \mathrm{kg}$ (body weight)/day for 15 days. The doses of 500 and $1000 \mathrm{ng} / \mathrm{kg} /$ day were chosen based on previous studies that determined TBT levels in South America marine coast ${ }^{[15,16]}$. The rats were euthanized after 15 days of treatment. Care was taken to avoid any major stress before sacrifice and the euthanasia procedure was completed within a few seconds. Immediately after euthanasia, thyroid gland was quickly removed and stored for histomorphology, thyroperoxidase (TPO) activity, H2O2 generation and western blot analysis.

\section{Behavioral Observation, Food Intake and Body Weight Gain}

Neurological changes as well as changes in the fur, feces and urine of animals were visually observed during the 15 days of treatment with TBT. The body weight and food intake were recorded by measuring the weight (grams) of the animals at the start and end of the treatment, and the daily measure of food consumed (grams) by the animals during treatment, respectively.

\section{Thyroid Gland Topographic and Histomorphometry Analyses} Thyroids from control and treated groups were immersed in $10 \%$ formalin's fixative solution $(\mathrm{pH}=7.4)$, dehydrated, clarificated and embedded in paraffin. Sections were cut 5- $\mu \mathrm{m}$ thick and stained with hematoxylin-eosin and PAS (Periodic Acid Schiff) for topographic and histomorphometry analysis, respectively. For topographic and histomorphometry proceedings, an image analysis system composed of a digital camera (Evolution, Media Cybernetics Inc., MD, USA) coupled to a light microscope (Eclipse 400, Nikon, NY, USA) was used. High quality images $(2048 \times 1536$ pixels $)$ were captured and analyzed using Pro Plus 4.5.1 software. Histomorphological parameters of the follicle cross-sections (epithelial height and area; follicle area and diameter; colloid area and diameter; and epithelial/colloid area ratio) were determined as described by Capen et al. ${ }^{[17]}$, Wade et al. ${ }^{[18]}$ (2002) and American Thyroid Association Guide to Investigating Thyroid Hormone Economy and Action in Rodent and Cell Models ${ }^{[19]}$, using 20 digital images/slide/animal.

\section{Collagen Fibers Quantification}

Thyroids from control and treated groups were fixed and cut $5 \mu \mathrm{m}$-thick sections as describe above, and slices were stained with picrosirius red for measurement of collagen deposition, an indicator of fibrosis. The picrosirius red staining quantification was performed using Image J digital software (National Institutes of Health, USA), using 30 digital/image/animal. All quantifications made in the slices were done only the central 
area of the thyroid slices, disregarding the marked areas of the capsule and major connective septa. The results obtained were expressed in percentage of marked area.

\section{Hormone Quantification}

Before the euthanasia (0, 7 and 15 days after begining the treatment) blood was collected in tubes coated with anticoagulant and centrifuged at $1500 \times \mathrm{g}$ for $15 \mathrm{~min}$ at $4^{\circ} \mathrm{C}$, and the plasma from each blood sample was separated and kept frozen at $-20^{\circ} \mathrm{C}$ until hormone quantification. Total serum $\mathrm{T}_{4}$ and $\mathrm{T}_{3}$ concentrations were measured using commercial kits of electrochemiluminescence from Roche Brazil (São Paulo, Brazil), according to manufacturer's instructions.

\section{Thyroperoxidase (TPO) Activity}

TPO iodide-oxidation activity was measured as previously described ${ }^{[20,21]}$. The assay mixture contained the following: $1.0 \mathrm{~mL}$ of freshly prepared $50 \mathrm{mM}$ sodium phosphate buffer $(\mathrm{pH}$ 7.4), containing $24 \mathrm{mM} \mathrm{KI}$ and $11 \mathrm{mM}$ glucose, and increasing amounts of solubilized TPO. The final volume was adjusted

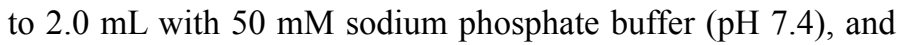
the reaction was started by the addition of $10 \mu \mathrm{L}$ of $0.1 \%(\mathrm{wt} /$ vol) glucose oxidase (Boehringer grade I). The increase in absorbance at $353 \mathrm{~nm}$ was registered for 3 minutes on a Hitachi spectrophotometer (U-3300, Tokyo, Japan). The $\Delta \mathrm{A} 353 \mathrm{~nm} / \mathrm{min}$ was determined from the linear portion of the reaction curve and related to the protein concentration. The protein concentration was determined by the Bradford assay ${ }^{[22]}$. Results were given in units per gram of protein ( $1 \mathrm{U}$ corresponds to $\Delta \mathrm{A} 353 \mathrm{~nm} / \mathrm{min}=$ $1.0)$.

\section{H2O2 Generation}

$\mathrm{H} 2 \mathrm{O} 2$ generation was quantified in thyroid particulate fractions by the Amplex red/horseradish peroxidase assay (Molecular Probes, Invitrogen, Carlsbad, California), which detects the accumulation of a fluorescent oxidized product, as previously described $^{[23]}$. For DUOX preparation, the excised thyroid glands remained at $4^{\circ} \mathrm{C}$ for 24 hours in $50 \mathrm{mM}$ sodium phosphate buffer (pH 7.2) containing $0.25 \mathrm{M}$ sucrose, $0.5 \mathrm{mM}$ dithiothreitol, 1 $\mathrm{mM}$ EGTA, $5 \mathrm{mg} / \mathrm{mL}$ aprotinin, and $34.8 \mathrm{mg} / \mathrm{mL}$ phenylmethylsulphonyl fluoride before homogenization. Then the homogenate was centrifuged at $100000 \mathrm{xg}$ for 35 minutes at $4^{\circ} \mathrm{C}$ and suspended in $0.25 \mathrm{~mL}$ of $50 \mathrm{mM}$ sodium phosphate buffer $(\mathrm{pH}$ 7.2) containing $0.25 \mathrm{M}$ sucrose, $2 \mathrm{mM} \mathrm{MgCl} 2,5 \mathrm{mg} / \mathrm{mL}$ aprotinin, and $34.8 \mathrm{mg} / \mathrm{mL}$ phenylmethylsulphonyl fluoride ${ }^{[24]}$. This particulate fraction was incubated in $150 \mathrm{mM}$ sodium phosphate buffer ( $\mathrm{pH}$ 7.4) containing $100 \mathrm{U} / \mathrm{mL}$ superoxide dismutase (SOD) (Sigma), $0.5 \mathrm{U} / \mathrm{mL}$ horseradish peroxidase (Roche, Indianapolis, Indiana), $50 \mu \mathrm{M}$ Amplex red (Molecular Probes, Eugene, Oregon), $1 \mathrm{mM}$ EGTA, with or without $1.5 \mathrm{mM} \mathrm{CaCl} 2$. Then $0.1 \mathrm{mg} / \mathrm{mL}$ NADPH was added and the fluorescence was immediately measured in a Victor X4 microplate reader (PerkinElmer, Norwalk, Connecticut) at $30^{\circ} \mathrm{C}$, using wavelength excitation at $530 \mathrm{~nm}$ and emission at $595 \mathrm{~nm}$. $\mathrm{H} 2 \mathrm{O} 2$ production was quantified using standard calibration curves ${ }^{[23]}$. The specific enzymatic activity was expressed as nanomoles of $\mathrm{H} 2 \mathrm{O} 2 /$ hours/ milligram of protein. Protein concentration was determined by BCA protein assay kit (Thermo Scientific, Rockford, USA) according to manufacturer's instructions.

\section{Western Blotting for DUOX and NOX4}

Total protein was extracted from thyroid glands and quantified using the BCA protein assay kit (Thermo Scientific, Massachusetts, USA). Whole-tissue protein extracts were resolved by SDS-PAGE and transferred to a polyvinylidene membrane (Bio-Rad, California, USA) using an electroblotter (Bio-Rad, California, USA). Membranes were blocked with $5.0 \%$ non-fat milk for $1 \mathrm{~h}$ at room temperature, followed by overnight incubation at $4{ }^{\circ} \mathrm{C}$ with primary antibodies to DUOX that recognize both DUOX1 and DUOX2 (polyclonal antibody, kindly provided by Dr Corinne Dupuy, Institut Gustave-Roussy, France) and NOX4 (anti-NOX4 primary anti- body NB1105885, Novus Biologicals, Littleton, Colorado) at a dilution of 1:5000 and 1:2000, respectively. Primary antibody binding was detected using HRP-conjugated secondary antibody (anti-rabbit, 1:2000, Southern Biotech, San Diego, USA) and Immunobilon Western Chemiluminescent HRP substrate (Millipore, Massachusetts, USA). We used Ponceau (Sigma, San Diego, USA) staining as loading control.

\section{Statistical Analysis}

Data obtained from body weight, food intake, thyroid morphometry, collagen fibers quantification and hormone levels were expressed as mean \pm standard deviation of three independent experiments. Statistical comparisons were carried out by one-way ANOVA followed by Dunnett's test. TPO and DUOX activity data were expressed as mean \pm SEM and analysed by Kruskal-Wallis test, followed by Dunn test. All statistical analysis was performed using GraphPad Prism 4.0. The differences were considered significant when $\mathrm{p}<0.05$.

\section{Results}

No visible neurological alterations were found in animals treated during 15 days with different doses of tributyltin. Similarly, no visible changes were observed in urine and feces during the time of treatment. However, we observed a reduction in body weight gain in the group treated with $500 \mathrm{ng} / \mathrm{kg} /$ day TBT when compared to the control group, in spite of the increased food intake during the treatment (Table 1).

Table 1: Body weight (g) and food intake (g) of Wistar rats before and after 15 days of treatment with TBT. ${ }^{a} \mathrm{p}<0.05$ vs. Control. $\mathrm{N}=15$ per group.

\begin{tabular}{|c|c|c|c|}
\hline & \multicolumn{2}{|c|}{ Body weight (g) } & $\begin{array}{c}\text { Food intake } \\
\text { (g) }\end{array}$ \\
\hline & Initial & Final & \\
\hline Control & $262.5 \pm 8.928$ & $311.3 \pm 9.535$ & $117.9 \pm 8.028$ \\
\hline TBT 500 ng/kg/day & $266.6 \pm 6.583$ & $304.1 \pm 4.440 *$ & $145.6 \pm 9.510^{*}$ \\
\hline TBT 1000 ng/kg/day & $237.5 \pm 7.805$ & $303.1 \pm 5.798$ & $126.8 \pm 5.631$ \\
\hline
\end{tabular}

\section{Thyroid Topographical and Morphometric Analysis}

In order to evaluate topographic and morphometric changes in thyroid gland architecture promoted by TBT we used $\mathrm{HE}$ and PAS staining, respectively. The topographical analysis of the thyroid slices from control and TBT groups demonstrated many follicles with cuboidal epithelial cells surrounded a cavity 
rich in eosinophilic material or colloid, besides a rich vascular stroma and parafollicular cells in control group (Figure 1A and B). No morphologic changes were observed in thyroid slices from control group, as expected (Figure $2 \mathrm{~A}$ and D). When we compared thyroid slices from $500 \mathrm{ng} / \mathrm{kg} /$ day TBT-treated group with control, we observed follicles with simple cuboidal and/ or squamous epithelial cells surrounding a cavity rich in eosinophilic material or colloid; moreover it can be seen that there is a richer vascular stroma, compatible with vascular congestion. In addition, it can be observed vacuolated cells throughout the slices of thyroids (Figure 1C and D) as visualized by H\&E staining. Using PAS staining to delineate basement membrane of follicle structures and apical membrane of follicular cells, we made the morphological analysis of all thyroid tissue experimental groups. In thyroid slices provided from control or TBT groups, we did not see any change in the area of the follicular epithelium (Figure 1E and F). On the other hand, we have found a significant reduction in follicle, colloid and epithelium areas in the thyroid of animals exposed to $1000 \mathrm{ng} / \mathrm{kg} / \mathrm{day}$ TBT.
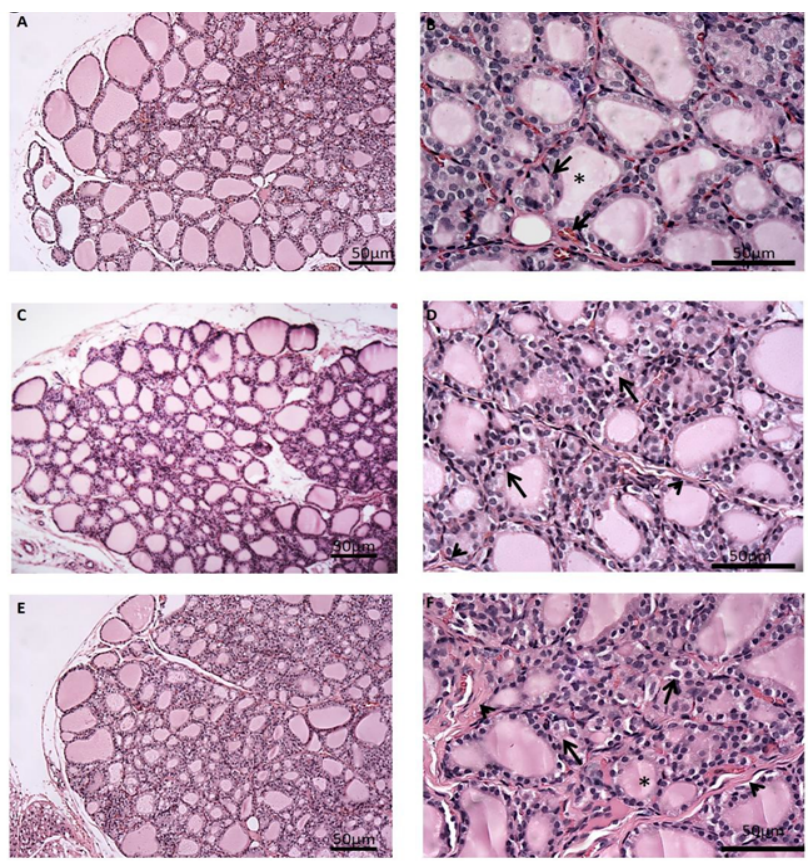

Figure 1: Topographical analysis of the thyroid gland of rats treated with TBT for 15 days (A and B) Control: note the simple cuboidal epithelium lining the majority of follicles, the area of colloid (asterisk) and blood vessels around the follicles (arrow). TBT $500 \mathrm{ng} / \mathrm{kg} /$ day (C and D): numerous vacuoles are observed in the follicular epithelium (arrow) and collagen deposition in the interfollicular region (head arrow). TBT $1000 \mathrm{ng} / \mathrm{kg} / \mathrm{day}$ (E and F): The follicular epithelium remains vacuolated (arrow), a greater deposition of interfollicular collagen (head arrow) and an apparent reduction in follicle area (asterisk) can be observed. Bars $=50 \mu \mathrm{m}$
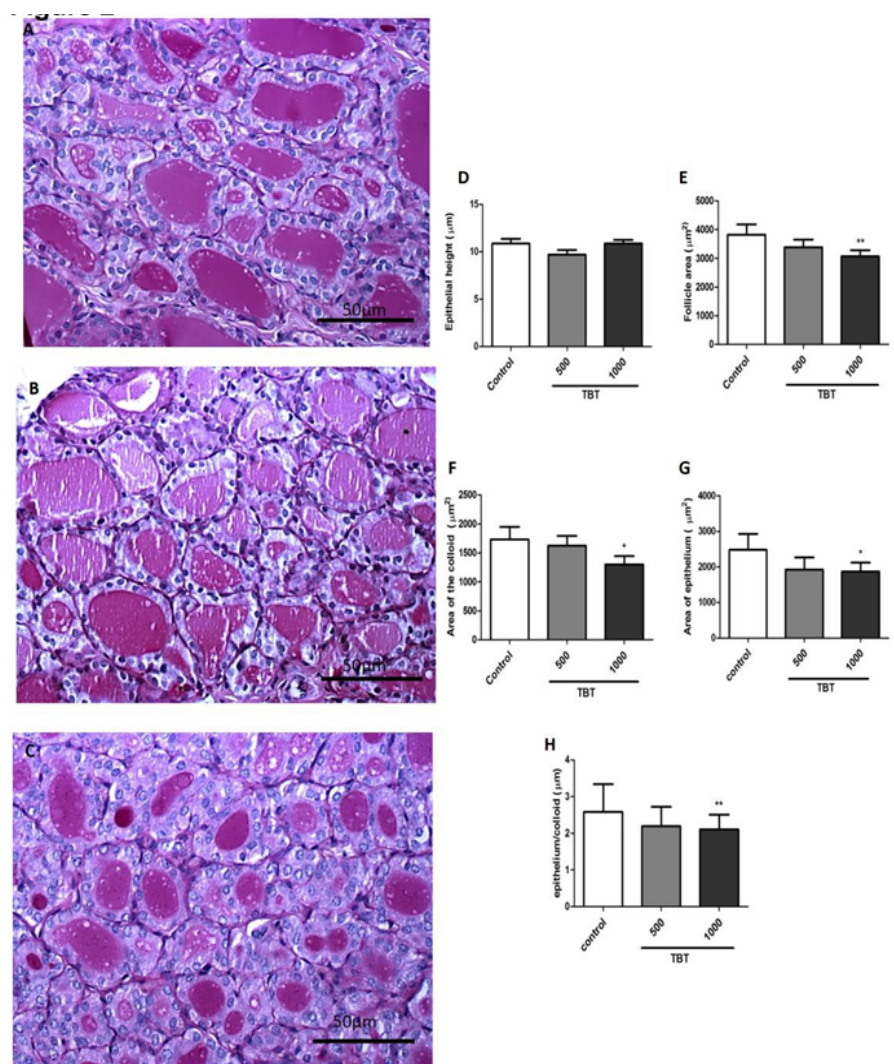

Figure 2: Histomorphometric analysis of the thyroid gland of rats treated with TBT for 15 days, stained with periodic acid Schift (PAS). Control (A); TBT $500 \mathrm{ng} / \mathrm{kg} /$ day (B); TBT 1000ng/kg/day (C) Epithelial height (D); Follicular area (E); Area of the colloid (F); Epithelial area (G); Epithelial/Colloid (H) ** P $<0.01$ vs. control; ${ }^{*} \mathrm{p}<0,05$ vs. control Scale bar $50 \mu \mathrm{m}$. $\mathrm{N}=5$ per group.

\section{Thyroid Collagen Deposition}

The next step was to evaluate collagen deposition in thyroid glands. An intense collagen deposition was found in thyroid glands from TBT-treated animals. Then, we used a picrosirius red staining to evaluate the amount of collagen fibers (type I and III) in interfollicular connective septa of thyroid glands. The collagen fibers quantification was made in central area of the thyroid slices and the percentage of marked area was determined (Figure 3A, B and C). Our data showed higher deposition of collagen in both groups treated with TBT when compared to control group (Figure 3D).
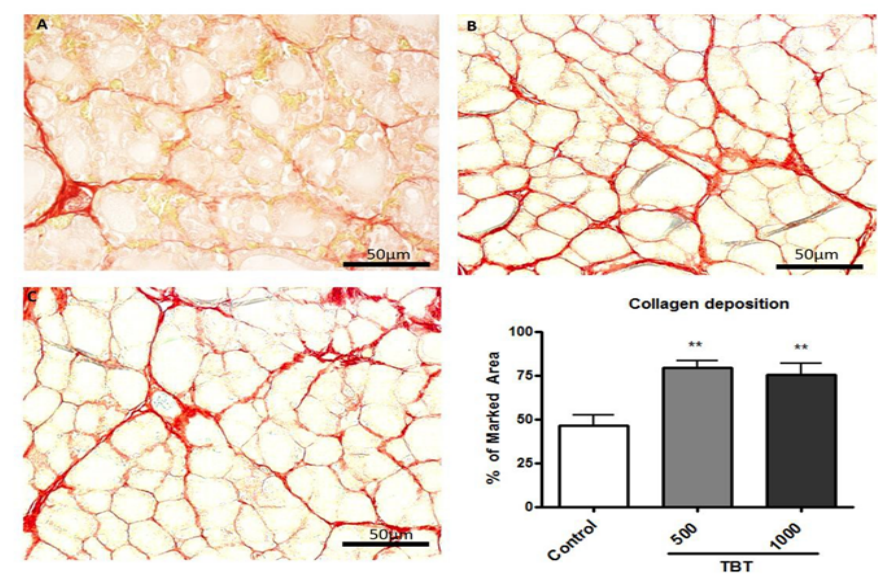

Figure 3: Analysis of collagen deposition in the thyroid gland of rats treated with TBT for 15 days, stained with picrosirius. Control (A); $500 \mathrm{ng} / \mathrm{kg} / \mathrm{day}$ TBT (B) and TBT $1000 \mathrm{ng} / \mathrm{kg} / \mathrm{day}$ (C).

$* * \mathrm{p}<0.01$ vs. control. $50 \mu \mathrm{m}$ scale bar. $\mathrm{N}=15$ per group. 


\section{Plasma Levels of total T3 and T4}

The plasma levels of T3 and T4 were determined in the beginning, the middle and at the end of treatment. No significant differences were observed in T3 and T4 plasma levels when compared to control in any time analyzed during the experiment (Figure $4 \mathrm{~A}$ and B). However, we detected a significant increase in T4 plasma levels into the same group when we compare different days of treatment ( 0,7 and 15 days), what was observed with both TBT treatments (500 and $1000 \mathrm{ng} / \mathrm{kg} /$ day) (Figure 4 B).

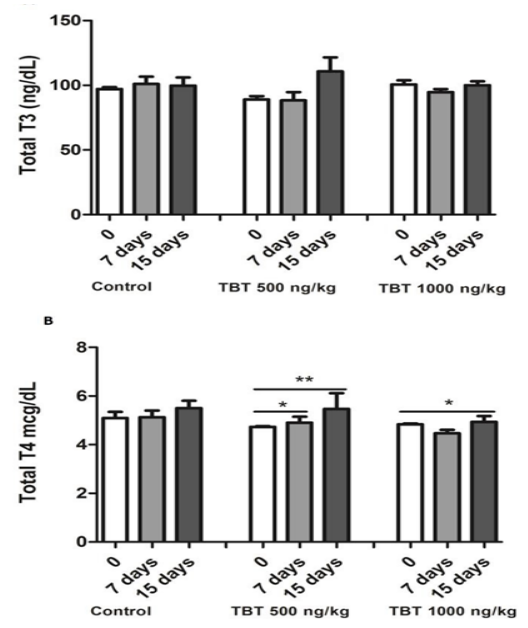

Figure 4: Total $\mathrm{T} 3$ and $\mathrm{T} 4$ concentration in the plasma of rats treated with TBT for 15 days. Total T3 (A) and total T4 (B) measured after 0,7 and 15 days of treatment. $* \mathrm{p}<0.05$ (timescale 0 vs. $7 ; 0$ vs. 15 days), $* * p<0.01$ (timescale 0 vs. 15 days). $\mathrm{N}=10$ per group

\section{H2O2 Generation and TPO Activity}

Since we have found an increase of collagen deposition in TBT treated animals, which could be related to an increment of oxidative stress in the gland, we then evaluated $\mathrm{H} 2 \mathrm{O} 2$ generation besides thyroperoxidase activity, an enzyme known to consume $\mathrm{H} 2 \mathrm{O} 2$ in the thyroid. Thyroid DUOX calcium-dependent $\mathrm{H} 2 \mathrm{O} 2$-generating activity was increased in $1000 \mathrm{ng} / \mathrm{kg} /$ day TBT group (Figure 5C), whereas TPO activity remained unchanged (Figure 5A). In addition, when we have analyzed $\mathrm{H} 2 \mathrm{O} 2$ generation in the absence of calcium, which have a trend to increase in TBT-treated groups, however the increment did not reach statistical significance (Figure 5D).
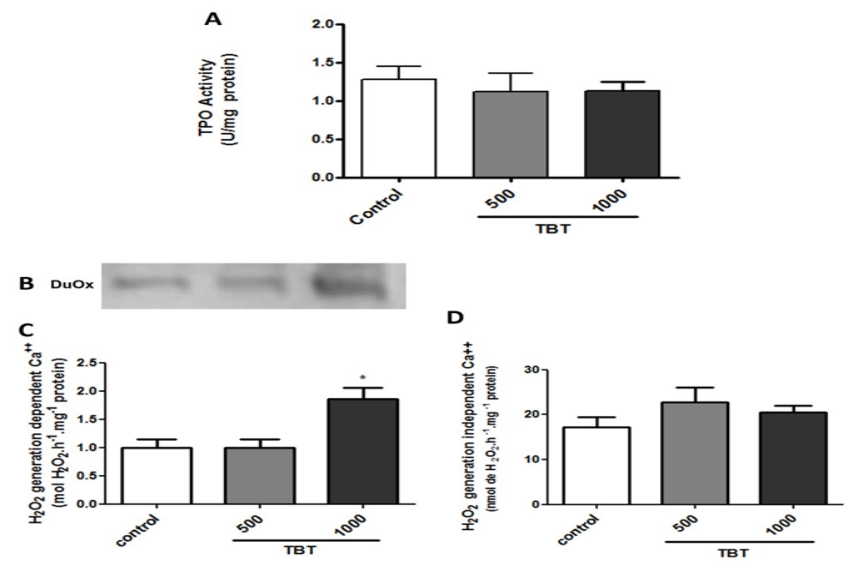

Figure 5: Thyroperoxidase (TPO) iodide oxidation activity and NADPH-dependent hydrogen peroxide generation in the thyroid of rats treated with TBT for 15 days. TPO activity (A), Duox protein expression (B) and calcium-dependent (C) and independent (D) hydrogen peroxide generation. $* * \mathrm{p}<0.01$ vs. control. $\mathrm{N}=10$ per group.

\section{DUOX and NOX4 Protein Expression}

To evaluate whether increased $\mathrm{H} 2 \mathrm{O} 2$ generation could be due to increased levels of DUOX and/or NOX4 protein, we have assessed this issue by western blotting analysis. As shown in Figure 5B TBT treatment led to increased DUOX protein content, which is in agreement with the increased calcium-dependent hydrogen peroxide generation seen in TBT- treated animals. On the other hand, NOX4 expression remained unchanged (data not shown), as was calcium-independent $\mathrm{H} 2 \mathrm{O} 2$ generation.

\section{Discussion}

Thyroid gland is an important organ of the endocrine system. It is responsible to produce thyroid hormones (THs), T3 and T4, and calcitonin. This endocrine gland is responsible for the production of hormones related to normal development, reproduction and metabolism and can be a target of a large variety of endocrine disruptors, among them, TBT.

Herein, we report important morphophysiological alterations in mammal's thyroid gland when submitted to tributyltin sub-acute exposure. Among OT compounds, we highlight tributyltin since, despite having been banned, there is still high amount of TBT in marine water that can contaminate seafood consumed by the population, and can be transferred through food chain and undergo bioaccumulation and biomagnification. Therefore, it is relevant to study the effects of TBT on mammals' endocrine system in particular on thyroid gland. Our study focused on parenchyma thyroid morphological and morphometric alterations as well as in enzymes important for TH biosynthesis. We found that TBT exposure promotes significant changes in follicle, colloid and epithelium areas in the thyroid of animals exposed to high concentration of TBT. We highlight, that thyroid from animals treated with high dose of TBT showed high quantities of microfollicular structures similar to that seen in follicular adenoma. This disorganization in thyroid parenchyma can contribute to loss of thyroid homeostasis.

Many environment contaminants provided from occupational and industrial chemicals are able to increase reactive oxygen species (ROS). These highly reactive chemical molecules lead to genotoxicity, which is suggested to contribute to the pathophysiology of many human diseases, including inflammatory diseases and cancer. Oxidative stress is defined as the imbalance between cellular oxidant and antioxidant systems ${ }^{[25,23]}$. ROS can be produced during normal cellular function or can emerge after exposure to environmental contaminants as TBT. ROS are very unstable and due to their high chemical reactivity can lead to lipid peroxidation, protein oxidation and degradation, DNA damage and/or mutagenesis ${ }^{[26-28]}$. It is known that the increased oxidative stress due to the overproduction of ROS may be related to increased collagen synthesis ${ }^{[29,30]}$ and intense interfollicular collagen deposition as well as vacuolization of follicular cells ${ }^{[18]}$. This event can be related to the high calcium-dependent $\mathrm{H} 2 \mathrm{O} 2$ production, as seen in adult male rat thyroid particulate fractions from TBT treated animals. The increased calcium-dependent $\mathrm{H} 2 \mathrm{O} 2$ generation seems to be due to the increment in DUOX protein expression, since the levels of this protein seem to be increased as evaluated by western blot. Recently, our group demonstrated that the thyroid gland of female rats is exposed to higher oxidative stress levels due both to increased ROS production through NOX4, and decreased ROS 
degradation, probably because of the high levels of estrogen ${ }^{[23]}$. Thus, continuous exposure to the redox imbalance is a risk factor in diseases such as thyroiditis and cancer, culminating in loss of thyroid parenchyma and altered organism homeostasis.

Even though serum T4 levels increased during the treatment with TBT in both doses when compared to basal levels, TPO activity did not differ among the groups. However, since the calcium-dependent $\mathrm{H} 2 \mathrm{O} 2$ production was increased by the higher dose of TBT, a greater availability of $\mathrm{H} 2 \mathrm{O} 2$ could be related to the increment in $\mathrm{T} 4$ production, since $\mathrm{H} 2 \mathrm{O} 2$ is limiting for thyroid hormonogenesis ${ }^{[31]}$. TPO and DUOX enzymatic activities were negatively correlated, as previously described in human goiters ${ }^{[31]}$ and in a cell culture model ${ }^{[32]}$, and recently the same was seen in diabetes mellitus model ${ }^{[33]}$, however in our study we didn't find it. We cannot exclude the possibility that a decreased thyroid hormone metabolism could contribute to the higher T4 levels seen in TBT-treated groups. Corroborating this observation, we have found inhibition of the type 2 deiodinase (D2) activity by TBT (data not shown). The metabolism of T3 and T4 via deiodination depends on type 1 (D1), type 2 (D2) and type 3 (D3) deiodinases ${ }^{[19]}$ (Bianco et al., 2002). These enzymes are essential for regulating the intracelular and plasma levels of thyroid hormones. Thus, inhibition of type 2 deiodinase activity could explain the increased plasma levels of T4.

It is important to underline that an increment in $\mathrm{H} 2 \mathrm{O} 2$ generation without changes in TPO activity could lead to an imbalance between ROS production and degradation, thus resulting in oxidative stress ${ }^{[33,23]}$. Therefore, the increased collagen deposition and the reduction of the follicle could be related to the oxidative stress in the thyroid gland. Thus, serious deleterious effects could be seen due to prolonged TBT exposure culminating in destruction of parenchyma and substitution by fibrous tissue.

\section{Conclusion}

The treatment of rats with TBT sub-acute exposure alters thyroid hormone serum levels and increase thyroid ROS production, besides increasing collagen deposition and reducing follicle, colloid and epithelial area; thus suggesting that TBT has a deleterious effect on thyroid homeostasis.

\section{Acknowledgment}

The authors thank Maria Aparecida de Oliveira Domingos and Ruy Louzada for technical assistance, and Prof. Dr. Christina Maeda Takiya and Prof. Dr. Rodrigo Soares Fortunato for critics commentaries, and Prof. Dr. Ana Luisa Palhares de Miranda for kindly provided the animals from Animal Facility of the Faculty of Pharmacy of the Federal University of Rio de Janeiro.

Disclosure Statement: No competing financial interests exist.

\section{Author Contributions}

Conceived and designed the experiments: PRP, CP, ACFF and LM-A. Performed the experiments: PRP, CP, RMN, DLG and RANL. Analyzed the data: PRP, CP, JBG, ACFF and LM-A. Contributed reagents/materials/analysis tools: LEN, DPC, ACFF and LM-A. Wrote the paper: PS, DPC, ACFF and LM-A.

\section{Financial Support}

This work was supported by Fundação Carlos Chagas Filho de Amparo à Pesquisa do Estado do Rio de Janeiro (FAPERJ/E-26/110.485./2014), Conselho Nacional de Desenvolvimento Científico (CNPq) and Coordenação de Aperfeiçoamento de Pessoal de Nível Superior (CAPES/Ciências sem Fronteiras/Pesquisador Visitante Especial/88881.062218/2014-0). The funders had no role in study design, data collection and analysis, decision to publish, or preparation of the manuscript.

\section{References}

1. Brtko, J., Dvorak, Z. Triorganotin compounds - ligands for "rexinoid" inducible transcription factors: Biological effects. (2015) Toxicol Lett 234(1): 50-58.

2. Alzieu, C. Environmental impact of TBT: the French experience. (2000) Sci Total Environ 258(1-2): 99-102.

3. Liu, L.L., Chen, S.J., Peng, W.Y., et al. Organotin concentrations in three intertidal neogastropods from the coastal waters of Taiwan. (1997) Environ Pollut 98(1): 113-118.

4. Ueno, S., Susa, N., Furukawa, Y., et al. Butyltin and phenyltin compounds in some marine fishery products on the Japanese market. (1999) Arch Environ Health 54(1): 20-25.

5. Shim, W.J., Kahng, S.H., Hong, S.H., et al. Imposex in the rock shell, Thais clavigera, as evidence of organotin contamination in the marine environment of Korea. (2000) Mar Environ Res 49(5): 435-451.

6. Okoro, H.K., Fatoki, O.S., Adekola, F.A., et al. Human exposure, biomarkers, and fate of organotins in the environment. (2011) Rev Environ Contam Toxicol 213: 27-54.

7. Alzieu, C.1., Sanjuan, J., Deltreil, J.P., et al. Tin contamination in Arcachon Bay: Effects on oyster shell anomalies. (1986) Mar Pollut Bull 17(11): 494-498.

8. Sonak, S., Pangam, P., Giriyan, A., et al. Implications of the ban on organotins for protection of global coastal and marine ecology. (2009) J Environ Manage 90(Suppl 1): S96-108.

9. Toste, R., Pessoa, I.A., Dore, M.P., et al. Is aphallic vas deferens development in females related to the distance from organotin sources? A study with Stramonita haemastoma. (2013) Ecotoxicol Environ Saf 91: 162-70.

10. Zhang, J., Zuo, Z., He, C., et al. Inhibition of thyroidal status related to depression of testicular development in Sebastiscus marmoratus exposed to tributyltin. (2009) Aquat Toxicol 94(1): 62-67.

11. Adeeko, A., Li, D., Forsyth, D.S., et al. Effects of in utero tributyltin chloride exposure in the rat on pregnancy outcome. (2003) Toxicol Sci 74(2): 407-415.

12. Cooke, G.M., Tryphonas, H., Pulido, O., et al. Oral (gavage), in utero and postnatal exposure of Sprague-Dawley rats to low doses of tributyltin chloride. Part 1: Toxicology, histopathology and clinical chemistry. (2004) Food Chem Toxicol 42(2): 211-220.

13. Shi, H., Zhu, P., Guo, S. Effects of tributyltin on metamorphosis and gonadal differentiation of Xenopus laevis at environmentally relevant concentrations. (2014) Toxicol Ind Health 30(4): 297-303.

14. Sharan, S., Nikhil, K., Roy, P. Disruption of thyroid hormone functions by low dose exposure of tributyltin: an in vitro and in vivo approach. (2014) Gen Comp Endocrinol 206: 155-65.

15. Godoi, A.F., Montone, R.C., Santiago-Silva, M. Determination of butyltin compounds in surface sediments from the São Paulo State coast (Brazil) by gas chromatography-pulsed flame photometric detection. (2003) J Chromatogr A 985(1-2): 205-210.

16. Sant'Anna, B.S., Santos, D.M., Marchi, M.R., et al. Surface-sediment and hermit-crab contamination by butyltins in southeastern Atlantic estuaries after ban of TBT- based antifouling paints. (2014) Environ Sci Pollut Res Int 21(10): 6516-6524.

17. Capen, C.C. Correlation of mechanistic data and histopathology in the evaluation of selected toxic endpoints of the endocrine system. 
(1998) Toxicol Lett 28(102-103): 405-409.

18. Wade, M.G., Parent, S., Finnson, K.W., et al. Thyroid toxicity due to subchronic exposure to a complex mixture of 16 organochlorines, lead, and cadmium. (2002) Toxicol Sci 67(2): 207-218.

19. Bianco, A.C., Anderson, G., Forrest, D., et al. American thyroid association guide to investigating thyroid hormone economy and action in rodent and cell models. (2014) Thyroid 24(1): 88-168.

20. de Carvalho, D.P., Rego, K.G., Rosenthal, D. Thyroid peroxidase in dyshormonogenetic goiters with organification and thyroglobulin defects. (1994) Thyroid 4(4): 421-426.

21. Ferreira, A.C., Lima, L.P., Araujo, R.L., et al. Rapid regulation of thyroid sodium-iodide symporter activity by thyrotrophin and iodine. (2005) J Endocrinol 184(1): 69-76.

22. Bradford, M.M. A rapid and sensitive method for the quantification of microgram quantities of protein utilizing the principle of protein dye binding. (1976) Anal Biochem 72(1-2): 248-254.

23. Fortunato, R.S., Braga, W.M., Ortenzi, V.H., et al. Sexual dimorphism of thyroid reactive oxygen species production due to higher NADPH oxidase 4 expression in female thyroid glands. (2013) Thyroid 23(1): 111-119.

24. Muhlbauer, M., da Silva, A.C., Marassi, M.P., et al. Retinoic acid modulation of thyroid dual oxidase activity in rats and its impact on thyroid iodine organi- fication. (2010) J Endocrinol 205(3): 271-277. 25. Mates, J.M., Segura, J.A., Alonso, F.J., et al. Intracellular redox status and oxidative stress: implications for cell proliferation, apoptosis, and carcinogenesis. (2008) Arch Toxicol 82(5): 273-299.
26. Hengstler, J.G., Bolt, H.M. Loss of DNA damage checkpoint genes: switch from preferential induction of point mutations to chromosomal damage precedes the transition towards an aggressive cancer type. (2008) Arch Toxicol 82(6): 341-342.

27. Maynard, S., Schurman, S.H., Harboe, C., et al. Base excision repair of oxidative DNA damage and association with cancer and aging. (2009) Carcinogenesis 30(1): 2-10.

28. Mates, J.M., Segura, J.A., Alonso, F.J., et al. Oxidative stress in apoptosis and cancer: an update. (2012) Arch Toxicol 86(11): 16491665.

29. Tsukamoto, H., Rippe, R., Niemelä, O., et al. Roles of oxidative stress in activation of Kupffer and Ito cells in liver fibrogenesis. (1995) J Gastroenterol Hepatol 10(1): S50-S53.

30. Poli, G., Parola, M. Oxidative damage and fibrogenesis. (1997) Free Radic Biol Med 22(1- 2): 287-305.

31. Ginabreda, M.G., Cardoso, L.C., Nobrega, F.M., et al. Negative correlation between thyroperoxidase and dual oxidase $\mathrm{H} 2 \mathrm{O} 2$ - generating activities in thyroid nodular lesions. (2008) Eur J Endocrinol 158(2): 223-227.

32. Fortunato, R.S., Lima de Souza, E.C., Ameziane-el Hassani, R., et al. Functional consequences of dual oxidase-thyroperoxidase interaction at the plasma membrane. (2010) J Clin Endocrinol Metab 95(12): 5403-5411.

33. Santos, M.C., Louzada, R.A., Souza, E.C., et al. Diabetes Mellitus Increases Reactive Oxygen Species Production in the Thyroid of Male Rats. (2013) Thyroid 154(3): 1361-1372. 